\title{
Study on Professional Quality of Students Majoring in Hotel Management Based on Post Demand
}

\author{
Jun Li \\ Shaanxi Vocational and Technical College Department of Tourism, Xi'an, 710100, China
}

\begin{abstract}
Keywords: post demand; hotel management major; college student; professional quality
\end{abstract}
\begin{abstract}
In view of continuous social development, the demand for talents also changes. It is difficult for employers to find suitable employees, while it is hard for graduates to land satisfying jobs. Under such background, professional quality cultivation for college students based on post demand has become an urgent task. This paper sets forth professional quality of students majoring in hotel management.
\end{abstract}

\section{Introduction}

Rational positioning of professional quality of college graduates is the precondition of specifying training objective of college students, formulating corresponding talent cultivation plan, preparing appropriate training program and issuing cultivation measures which more comply with post demand. Professional quality cultivation for college students majoring in hotel management is more urgent. So, the author explores professional quality cultivation for college students majoring in hotel management, in the hope of better cultivating high-quality graduates majoring in hotel management who accord with post demand.

\section{Professional quality connotation of students majoring in hotel management}

Professional quality of college students is not equal to vocational skill. Vocational skill is one of contents of professional quality. The concept of professional quality is wider. Through researches for many years, the author has his own cognition of professional quality structure of college students. Professional quality not just includes techniques related to working ability, but also contains the two parts: 1) strong employment situation judgment and analysis ability for job market changes. If college students own professional quality, they can objectively analyzes and judges their employment situations so as to better master current social economic prospect, enterprise development conditions, know and understand many change factors of job market so that graduates can have better psychological quality to make preparations for employment. 2) Good at analyzing their employability in an all-round way and implementing vocational positioning objectively and rationally. How to choose appropriate occupations? What jobs should be selected? What's the first post after graduation? How to handle post adaptation problem? These belong to the scope of whether college students can correctly occupational positioning.

Professional quality of students majoring in hotel management is different from that of students of other majors. Professional quality of graduates majoring in hotel management should not just owns the quality required for general college students, but also should at least have the following two features: 1) own quite strong service awareness or service ability. This is because hotel industry belongs to the tertiary industry, i.e. service industry. This industry is different from the primary industry or the secondary industry. Its marketing mode is direct supply of services for customers, and its products are services. In view of this, practitioners of hotel management must own very good service awareness. Thus, colleges should continuously teach students service concept in the whole teaching process so that they can form service awareness when they graduate. 2) Own favorable art and culture temperament. This is because the hotels where college graduates majoring in hotel management are of high grade. Especially as living conditions of modern people improve, the requirements for hotel services become higher and higher. So, enterprises have high 
requirements and larger cultivation expectations for students majoring in hotel management, and lay particular stress on their culture and art temperament, including favorable appearance and accomplishment.

\section{Necessity of implementing professional quality education for students majoring in hotel management}

At present, employment situation of college students is faced with a dilemma: labor shortage of enterprises and difficulty in job hunting for college graduates. This situation arises from multiple factors. Especially for hotel industry, due to sustainable economic development and structural adjustment, the demand for high-quality hotel management talents is on the rise. Meanwhile, an increasing number of colleges set up tourism management and hotel management majors. However, through interview and survey of human resource departments of high star-level hotels in some cities, the author learns that, although more and more colleges start to cultivate professional hotel management talents, related college students are often unwilling to start from service work at the grass root. It is hard for those with low academic background to meet quality requirements of high star-level hotels. On this account, hotel management graduates with high professional quality become the talents urgently needed by high star-level hotels. In order to practically satisfy market post demand, colleges should strive to explore a new approach which can meet post demand and is suitable for professional quality cultivation of college students on the basis of cultivating practical talents.

\section{Basic contents of professional quality cultivation of students majoring in hotel management based on post demand}

For graduates majoring in hotel management, professional quality they must own mainly includes the following four aspects. Firstly, they should own favorable professional ideal and moral sentiments. Workers in hotel industry must have very strong professional dedication so as to throw themselves into work heart and soul and seek joys. Meanwhile, graduates must possess professional awareness,. For college graduates, grass-roots service post work of hotel management industry is certainly very hard. Workers must own very strong will and perseverance to do the job well. Besides, they should accumulate corresponding management experience from tough training so as to gradually grow into qualified hotel management workers. Secondly, graduates should have proficient professional skills. College graduates majoring in hotel management need to own quite strong communication ability. Thus, college graduates should not just speak standard Chinese mandarin fluently, but also need to master corresponding foreign language competence. On this basis, in allusion to different posts, graduates are required to grasp corresponding professional operation skills, such as catering table preparation and table setting skills, guest meeting skills, check-in and settling system operation skills etc. Thirdly, graduates should possess very strong service awareness. Serving each guest is an inexorable law very hotel management worker must firmly abide by. High-quality and high-standard services can leave very good experience for guests. Such experience may attract guests to continue to select this hotel next time. It thus can be seen that favorable service is the root for the survival of a hotel to a large extent. Finally, graduates should own standardized occupational etiquette. Such occupational etiquette norms include clothing, make-up and etiquette. Hotel workers generally require wearing uniform, which can not just reflect uniform enterprise culture, but also can make guests distinguish different work posts more clearly. Amiable and elegant appearance is also a quality hotel workers must own.

\section{Main methods for hotel management students to develop professional quality based on post demand}

Firstly, promote students' learning interest. College students should select specialized subjects so as to better improve their interest in the major. College students majoring in hotel management 
should according to their interests to choose the courses they are interested in. in this way, they can not merely enjoy the whole learning process of hotel management major, but also can subtly improve their interest in hotel management major. Moreover, they can deepen understanding of the major through listening to lectures and participating in interactions.

Secondly, cultivate students' professional ethics. Professional ethics is a good quality workers should strictly abide by, mainly including dedication, bearing hardships, standing hard work, abiding by rules, due diligence and integrity etc. Workers should own special skills required by posts. Nowadays, every employer requires employees owning such professional quality as honesty and interpersonal cooperation. Graduates majoring in hotel management should pay high attention to requirements put forward by enterprises and gradually cultivate good professional quality so as to boost competitiveness in job market and lay a firm foundation for better adapting posts. The author feels workers of hotel management must throw themselves into work heart and soul, bear loneliness, start from the grass roots and require themselves doing the things before asking others to do them. This is very important for college students majoring in hotel management and also important basis for colleges to cultivate their professional ethics.

Thirdly, construct favorable knowledge structure for students. Knowledge learned by college students is mainly classified into two types: basic knowledge and professional knowledge. The former is the root, while the latter is an important key for future jobs. The above two supplement each other. Solid basic knowledge is the precondition. We should always pay high attention to professional foundation, fully respect and understand hotel management major and should definitely not lose their confidence. Colleges can also full combine actual conditions of education and teaching and specify theory teaching objective according to features of hotel management major. It is required to combine practical situations of local economic development, more actively construct characteristic courses suitable for local hotel management status so as to more fully reflect connection between theory teaching and post need. It is required to pay high attention to protecting and perfecting course construction of hotel management major, continuously update and adjust teaching contents of specialized courses and strive to achieve the objective of being big and strong. Colleges should set some optional courses of quality education as far as possible in combination of improving quality of hotel management workers and strive to fulfill interpenetration and seamless joint between professional education and vocational education in theory learning link. For example, lobby management course can be combined with room service course so that students can well combine theory and practice and better understand knowledge and apply it in practice.

Fourthly, guide students for professional practice. Professional practice teachers should work out clear and rational training plan according to teaching objectives. Training plan should be detailed as far as possible, lay emphasis on practice effects and guarantee interests of training units. It is better to establish stable training bases. Dual education function of enterprises and colleges should be exerted fully. The training hotels, colleges and students should achieve consistence as far as possible to maximize the benefit of practice link. Colleges should sign formal training base cooperation agreement with training hotels, enhance internal communication and create harmonious training environment. Besides, colleges should ensure legal interest of interns and hotels, implement strict quality monitoring, construct more scientific and rational assessment system, continuously perfect training contents, deepen cooperation force, make the purpose of studying knowledge in order to apply it and then promote practical activities of hotel management major to step in normal track.

Fifthly, teach students to conduct analogue simulation. It is required to intensify training room construction for hotel management major. This is because practicalness of hotel management is very strong. It is necessary to fully apply conditions of training room, design and implement educational integration of hotel management major. Of course, in analogue simulation courses, teachers can adopt many teaching methods including situational simulation teaching, role play teaching and task decomposition teaching to design integrated courses of hotel management major so that college students can seemingly be in real working environment, act as various talents in hotel operation, accept various tasks assigned by the superior, conduct teamwork and finally complete learning of 
integrated courses.

Sixthly, give play to guiding function of famous teachers. Hotel work is rich and colorful. Only when college students really place themselves in hotels can they better innovate thinking and improve their professional quality. To inject more vigor for students majoring in hotel management, it is required to transplant brand-new hotel management concept, strive for internal professional managers and seniors to serve as visiting professors for hotel management major, impart their modern hotel management experience and methods to handle complex problems and the latest news of hotel industry, cultivate students' working enthusiasm for hotel service industry and help them actively throw themselves into the industry.

\section{Conclusions}

In general, in the face of continuous development of current society, higher education also encounters new challenges. Thus, it is necessary to carry out professional quality cultivation for students majoring in hotel management according to features of college students and post demand of hotel management industry so as to really reach people first and deduction in the whole process and really make hotel management students to practical talents needed by employers.

\section{References}

[1] Xie Hourong, Hoe to cultivate professional quality of higher vocational college students [J]. Journal of Educational Institute of Jilin Province (subject), 2010 (8)

[2] Ye Juzhen, Approaches and methods to implement professional quality education for higher vocational college students [J]. Journal of Nanjing Institute of Industry Technology, 2010 (3)

[3] Ma Wei, Strategies to improve professional quality of college students under new situation [J]. Labor Union Forum, 2011 (2)

[4] Xiong Wei, Fang Xing, Review of moral education mode for Chinese colleges [J]. China Urban Economy, 201 (30)

[5] Ke Ling, Chen Jing, Liu Lvgao, Exploration of educational management mode of urban college students [J]. Business Research, 2012 (2) 